\title{
Chordoid glioma of the third ventricle
}

\author{
Mehrzad Zarghouni, MD, Clayton Vandergriff, MD, Kennith F. Layton, MD, J. Brad McGowan, MD, Caetano Coimbra, MD,
} Amol Bhakti, MD, and Michael J. Opatowsky, MD

A chordoid glioma is a rare low-grade tumor that arises from the anterior wall or roof of the third ventricle. It is postulated that this tumor originates from the ependymal cells of lamina terminalis (1). These slowly growing tumors are more common in females and are predominantly seen in the adult population. Most commonly, this tumor presents with clinical signs and symptoms of obstructive hydrocephalus to include nausea and headache (2), although endocrine imbalances, visual disturbances, and dysautonomia have also been reported.

The best imaging diagnostic tool for evaluation of chordoid gliomas is magnetic resonance imaging (MRI) of the brain with gadolinium. Typically, these tumors are well circumscribed, round or oval in shape, with T2 images showing iso- to hyperintense third-ventricle masses with avid homogenous enhancement (2) (Figure 1). Cystic changes are infrequently seen within the periphery of these tumors (3). On computed tomography (CT) scans, a chordoid glioma presents as a hyperattenuating mass arising from the third ventricle that homogeneously enhances following contrast administration (Figure 2).

Differential considerations for an anterior third ventricle mass in an adult include a colloid cyst, germinoma, ependymoma, macroadenoma, and chordoid glioma. A colloid cyst is predominantly a nonenhancing cystic lesion located at the foramen of Monro. Ependymomas usually extend into the third ventricle centered at the foramen of Monro. Macroadenomas are enhancing masses involving the pituitary gland. Germinomas also arise from the pituitary stalk. Therefore, based on the imaging characteristics of this lesion, a chordoid glioma is favored.

Complete surgical resection is considered the treatment of choice for these neoplasms. The deep anatomic location of these tumors places the patient at increased risk of surgical morbidity and mortality. Although the neoplasm is ventricle.
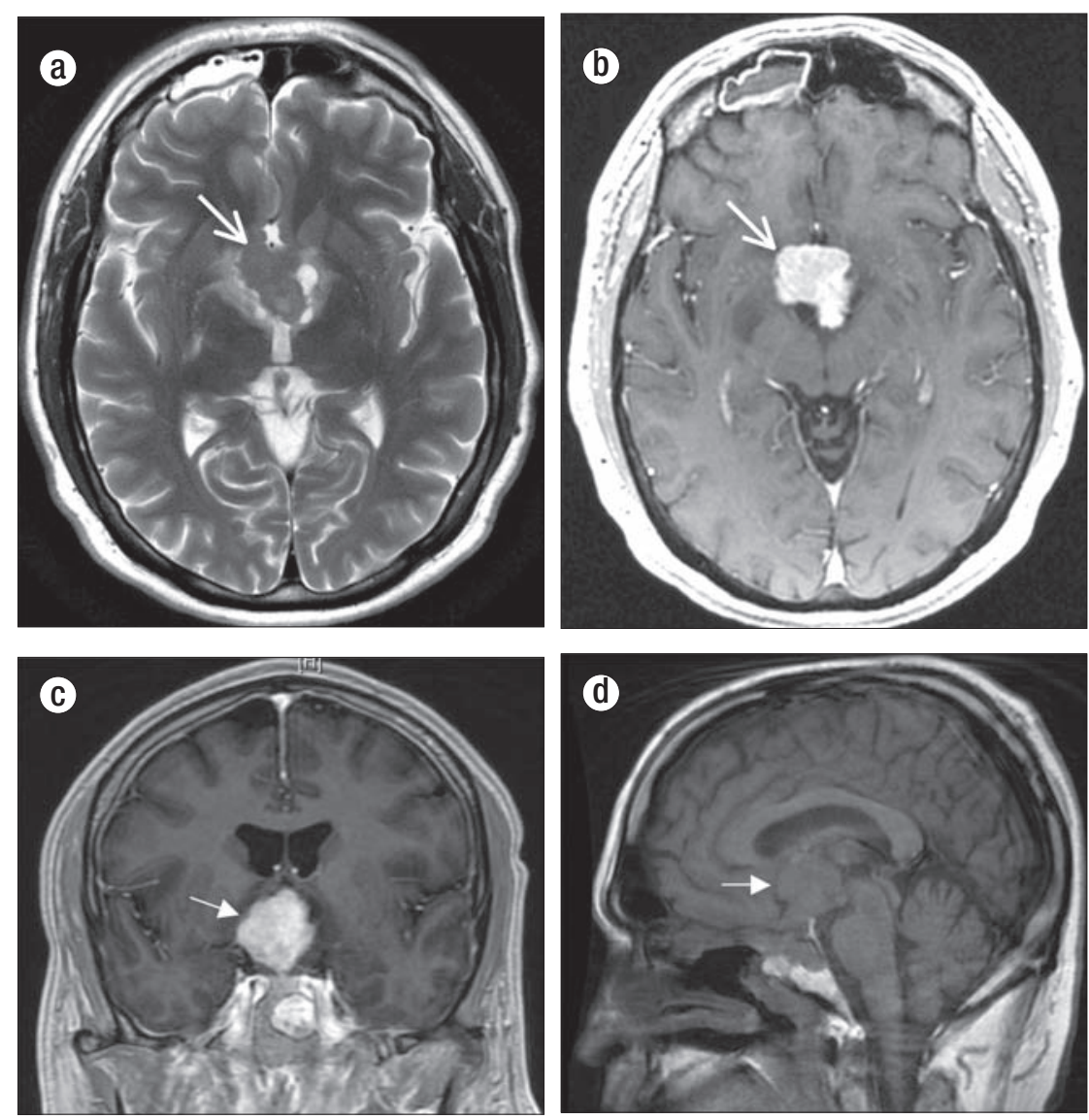

Figure 1. MRI images of chordoid glioma. (a) T2 axial, (b) postgadolinium T1 axial, (c) postgadolinium T1 coronal, and (d) T1 sagittal MRI images show a multilobulated homogeneously enhancing mass centered within the region of the anteroinferior third ventricle (arrow). On T2 images, cystic peripheral changes were also present. This lesion was pathologically proven to be a chordoid glioma of the third

low grade, incompletely resected tumors will continue slowly growing and may require later re-resection with the possibility of poorer clinical outcomes (3).

Our patient initially presented with symptoms of visual disturbance, endocrinopathy, and pituitary dysfunction. Following

From the Department of Radiology, Baylor University Medical Center at Dallas. Corresponding author: Michael J. Opatowsky, MD, Department of Radiology, Baylor University Medical Center at Dallas, 3500 Gaston Avenue, Dallas, Texas 75246 (e-mail: mjorad@aol.com). 

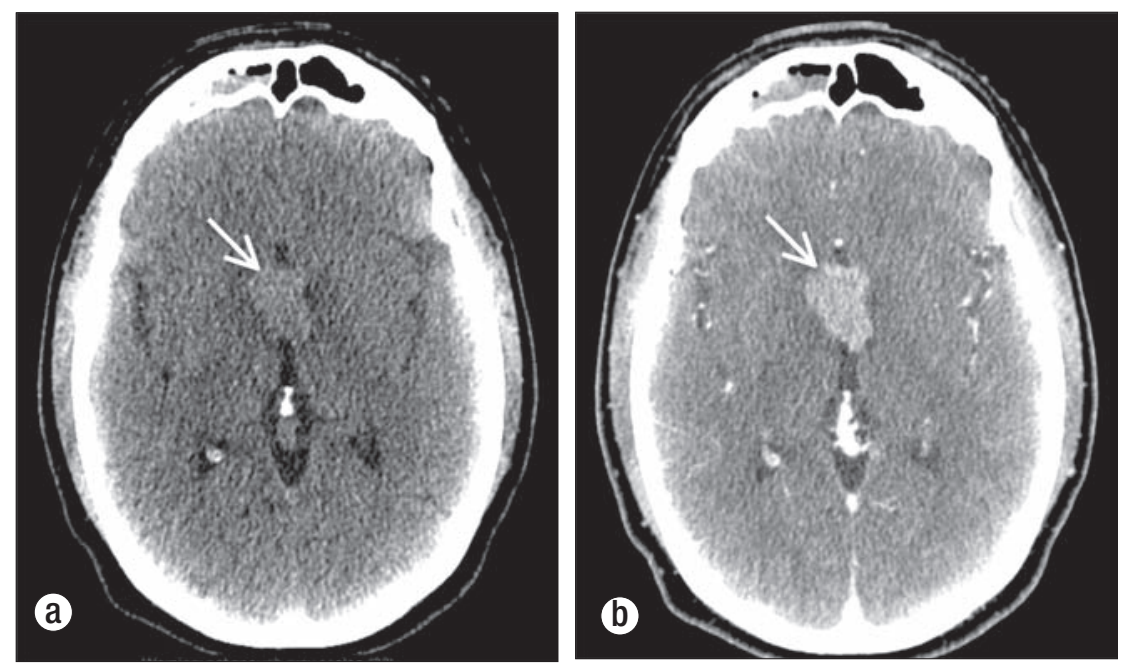

surgical resection and stereotactic radiosurgery, the patient experienced improvement in vision, an unchanged endocrinopathy, and no newly acquired pituitary dysfunction.

1. Ricoy JR, Lobato RD, Báez B, Cabello A, Martínez MA, Rodríguez G. Suprasellar chordoid glioma. Acta Neuropathol 2000;99(6):699-703.

2. Pomper MG, Passe TJ, Burger PC, Scheithauer BW, Brat DJ. Chordoid glioma: a neoplasm unique to the hypothalamus and anterior third ventricle. AJNR Am J Neuroradiol 2001;22(3):464-469.

3. Glastonbury CM, Osborn AG, Salzman KL. Masses and malformations of the third ventricle: normal anatomic relationships and differential diagnoses. Radiographics 2011;31(7):1889-1905.

Figure 2. CT images of chordoid glioma. (a) Precontrast and (b) postcontrast CT images reveal an enhancing mass arising from the inferior recess of the third ventricle (arrow). 